\title{
A BIBLIOGRAPHICAL NOTE
}

In many instances I have been able to include the reference within the text and have done so. In other instances, where the material referred to would clarify the discussion for the reader unfamiliar with Hume, the reference has been footnoted. In other words, sources for quotations are usually cited in the text, while explanatory material, even from the source, is cited in a footnote.

For the most part, quotations from Hume's literary and philosophical works have been taken from the Green and Grose edition; the Dialogues concerning Natural Religion is the major exception. The references to material from the Treatise of Human Nature and the two Enquiries also include a page reference to other editions of those works, since the Green and Grose is not always available, even in university libraries. The reader who compares the other editions to Green and Grose will no doubt discover a number of errors, as I did, in the Hendel and, especially, in the Selby-Bigge texts. The problem in regard to the History of England is even greater, since this work is more often ignored than consulted in any study of Hume. Quotations from it include in Roman numerals the chapter source, for example, History, V, Chap. XL, 160-161. All quotations are reproduced exactly as they appear in the text; no "modernization" has been attempted in reproducing Hume's letters or the History. Readers checking quotations from the History will encounter some difficulties: textual corruption is a constant companion to each successive reprint of the History. Even editions labelled "with the author's last corrections and improvements, to which is prefixed a short account of his life, written by himself" cannot be trusted. I have used an edition printed in Hume's lifetime because it would seem to obviate most of the errors, although it does not incorporate the "last corrections." I hope that I have introduced no further errors. 